\title{
CuO-Nanoparticles Catalyzed Synthesis of 1,4-Disubstituted-1,2,3-Triazoles from Bromoalkenes
}

\author{
JOHN PAUL RAJ ${ }^{\mathrm{b}}$, DASARI GANGAPRASAD ${ }^{\mathrm{b}}$, MURUGESAN VAJJIRAVEL $^{\mathrm{b}}$, \\ KESAVAN KARTHIKEYAN ${ }^{\mathrm{b}}$ and JEBAMALAI ELANGOVAN ${ }^{\mathrm{a}, *}$ \\ ${ }^{a}$ Department of Chemistry, Rajah Serfoji Government College, Thanjavur, Tamilnadu 613 005, India \\ ${ }^{\mathrm{b}}$ Department of Chemistry, B. S. Abdur Rahman Crescent Institute of Science \& Technology, Seethakathi Estate, \\ Vandalur, Chennai, Tamilnadu 600 048, India \\ E-mail: elangoorganic@gmail.com
}

MS received 4 January 2018; revised 3 March 2018; accepted 15 March 2018; published online 13 April 2018

\begin{abstract}
A novel and efficient protocol involving commercially available CuO nanoparticles (CNP) as catalyst has been developed for the synthesis of 1,2,3-triazoles. A library of 1,4-disubstituted 1,2,3-triazoles has been constructed with good to excellent yields.
\end{abstract}

Keywords. 1,2,3-Triazoles; [3+2] Cycloaddition; bromoalkenes; $\mathrm{CuO}$ nanoparticles.

\section{Introduction}

Despite the traditional Huisgen cycloaddition, ${ }^{1,2} 1,2,3-$ triazoles have drawn the attention of the scientific fraternity after the invention of copper-catalyzed azidealkyne cycloaddition (CuAAC) $)^{3,4}$ owing to its amazing regio-selectivity, functional group tolerance and operational simplicity. Even though 1,2,3-triazoles have not been isolated from natural sources, ${ }^{5}$ they have unveiled new horizons in various areas such as drug discovery, ${ }^{6,7}$ materials,,${ }^{8,9}$ polymers ${ }^{10}$ and supramolecules. ${ }^{11,12}$ Besides their usage as synthetic intermediates, ${ }^{13-15}$ they have also enormously contributed to the industry as photo stabilizers, corrosion inhibitor, dyes, fluorescent whiteners and optical brightening agents. ${ }^{16,17}$ Subsequently, Ruthenium-catalyzed azide-alkyne cycloaddition (RuAAC) was developed to prepare the complementary 1,5-disubstituted 1,2,3-triazoles. ${ }^{18-20} \mathrm{How}$ ever, alternative methods were sought out in the place of azide-alkyne cycloaddition since the synthetic and economic viability of alkynes emerged as a serious difficulty. In response to this need, olefins were envisaged in the place of alkynes since they have a better synthetic and commercial accessibility than alkynes.
This was ingeniously accomplished by oxidative azideolefin cycloaddition (OAOC) and eliminative azideolefin cycloaddition (EAOC). In OAOC, the triazoline formed by azide-olefin cycloaddition would concomitantly be oxidized into the corresponding triazole (Eq. 1a, Scheme 1). Whereas in EAOC, the olefin bearing a leaving group would undergo cycloaddition with the azide and the resulting triazoline would subsequently undergo elimination reaction to furnish the triazole (Eq. 1b, Scheme 1). In OAOC, electron-deficient olefins have been subjected to react with azides using various catalysts such as $\mathrm{Cu}(\mathrm{OTf})_{2}, \mathrm{Ce}(\mathrm{OTf})_{3}, \mathrm{Cu}(\mathrm{OAc})_{2}, \mathrm{CuI}$, $\mathrm{CuO}$ and $\mathrm{Fe}_{2} \mathrm{O}_{3}$-nanoparticles. ${ }^{21-26}$ Whereas in EAOC, olefins bearing the leaving groups such as alkoxy, ${ }^{27,28}$ acetate, ${ }^{29}$ nitro $^{30-34}$ and sulfone ${ }^{35,36}$ would be treated with azides to afford the triazoles. Another flamboyant category of EAOC is 'organo click reactions' in which electron-rich olefins such as enamines generated in situ would be treated with azides in the presence of organo catalysts such as secondary or tertiary amines. ${ }^{37}$ In continuation of our previous contributions in azideolefin cycloaddition of electron-deficient olefins and organic azides using $\mathrm{CuO}$ nanoparticles, ${ }^{38-41}$ we were prompted to examine the azide-olefin cycloaddition on

\footnotetext{
*For correspondence

Electronic supplementary material: The online version of this article (https://doi.org/10.1007/s12039-018-1452-1) contains supplementary material, which is available to authorized users.
} 


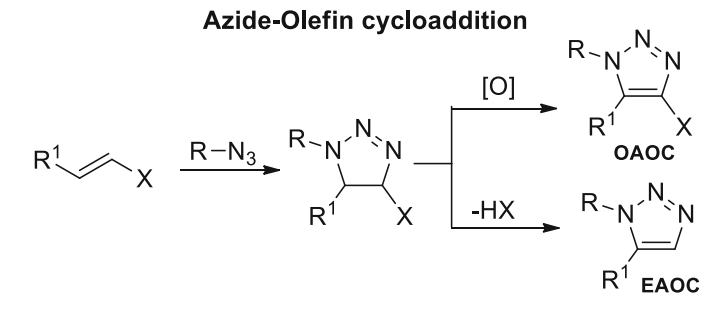

(1a)

1,2,3-Triazoles from bromoalkenes

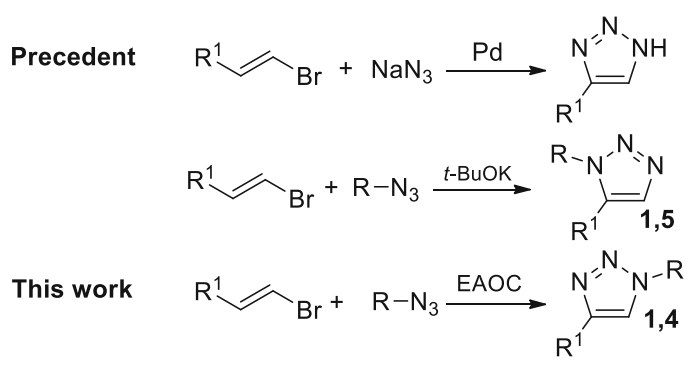

Scheme 1. Background of EAOC of bromoalkenes and organic azides.

bromoalkenes and organic azides. Our literature perusal on this aspect revealed the palladium-catalyzed synthesis of $1 H$-1,2,3-triazoles from sodium azide and alkenyl bromides (Eq. 2, Scheme 1). ${ }^{42}$ Besides that, basepromoted synthesis of 1,5-disubstituted 1,2,3-triazoles from alkenyl bromides and organic azides also has been reported in the literature (Eq. 3, Scheme 1). ${ }^{43}$ Kuang et al., described Cu-catalyzed synthesis of $1 \mathrm{H}$ 1,2,3-triazoles from 1,1-dibromoalkenes and sodium azide. ${ }^{44}$ Herein we report the synthesis of the complementary 1,4-disubstituted-1,2,3-triazoles from bromoalkenes and organic azides catalyzed by commercially available $\mathrm{CuO}$ nanoparticles (Eq. 4, Scheme 1).

\section{Experimental}

\subsection{Materials and methods}

All melting points were taken on Guna melting point apparatus and are uncorrected. High- resolution mass spectra were recorded on a JEOL GC Mate using electron impact ionization (EI) techniques. NMR spectra were obtained on a Bruker Ascend TM 400 NMR spectrometer; ${ }^{1} \mathrm{H}$ NMR and ${ }^{13} \mathrm{C}$ NMR spectra were recorded at $400 \mathrm{MHz}$ and $100 \mathrm{MHz}$ respectively. The chemical shifts were reported in ppm downfield to TMS $(\delta=0)$ for ${ }^{1} \mathrm{H}$ NMR and relative to the middle $\mathrm{CDCl}_{3}$ resonance $(\delta=77.0)$ for ${ }^{13} \mathrm{C}$ NMR. In the ${ }^{13} \mathrm{C}$ NMR spectra and the coupling constant $(J)$ is given in Hz. For thin-layer chromatography (TLC), silica gel plates Merck $60 \mathrm{~F}_{254}(0.25 \mathrm{~mm}$ thick) were used and compounds were visualized by irradiation with UV light and/or by treatment with Iodine. Column chromatography was performed either with Merck silica gel 60 (230-400 mesh) in common glass columns.

\subsection{General Procedure for the Synthesis \\ of 1-benzyl-4-phenyl-1H-1,2,3-triazole}

A mixture of bromostyrene $(0.5 \mathrm{mmol})$, benzyl azide $(1 \mathrm{mmol})$, $\mathrm{CuO}$ nanoparticles $(50 \mathrm{~mol} \%)$ and piperidine $(1 \mathrm{~mL})$ as a solvent were heated at $110^{\circ} \mathrm{C}$ for $12 \mathrm{~h}$. Completion of the reaction was monitored by TLC and the reaction mixture was cooled to room temperature. The resulting crude product was purified by column chromatography.

\subsection{Spectral data of representative compounds}

2.3a 1-benzyl-4-phenyl-1H-1,2,3-triazole (3a): White solid, M.p.: $126-128^{\circ} \mathrm{C},{ }^{1} \mathrm{H}$ NMR $\left(400 \mathrm{MHz}, \mathrm{CDCl}_{3}\right): \delta 7.81-7.79$ (m, 2H), $7.66(\mathrm{~s}, 1 \mathrm{H}), 7.42-7.36(\mathrm{~m}, 5 \mathrm{H}), 7.33-7.29(\mathrm{~m}, 3 \mathrm{H})$, $5.58(\mathrm{~s}, 2 \mathrm{H}) \mathrm{ppm} .{ }^{13} \mathrm{CNMR}\left(100 \mathrm{MHz}, \mathrm{CDCl}_{3}\right) \delta 148.3,134.7$, $130.6,129.2,128.8,128.2,128.1,125.7,119.5,54.3 \mathrm{ppm}$.

\section{Results and Discussion}

At the outset, we embarked on our examination with $\beta$ bromostyrene (1a) and benzyl azide (2a) as the reference substrates with $\mathrm{CuO}$ nanoparticles in DMSO. Though we initially anticipated the 4-bromo-1,2,3-triazole by oxidative azide-olefin cycloaddition, we were surprised to see 1,4-disubstituted triazole (3a) in $60 \%$ yield which was accompanied by $15 \%$ of the other regioisomer 4a (Table 1, entry 1). When $n$-octane was employed as the solvent in the place of DMSO, the yield of the triazole (3a) subsided to $20 \%$ (Table 1, entry 2). When other solvents such as chloroform, tetrahydrofuran, nitromethane, toluene and DMF were examined, only trace amount of the product (3a) was obtained (Table 1, entries 3-7). It is worth mentioning that the water has also failed to promote the reaction with a pronounceable yield of the product yield of 3a (Table 1, entry 8). When we envisaged a basic condition for this transformation, we employed piperidine entrusted with a dual role as the base and solvent. Our expectation was vindicated with $90 \%$ yield of $\mathbf{3 a}$ as the sole product (Table 1, entry 9). When the temperature of the reaction was gradually elevated from $90^{\circ} \mathrm{C}$ to $110^{\circ} \mathrm{C}$, the yield of the product (3a) precipitously hiked to $97 \%$ (Table 1, entries 9-11). Subsequently, while other organic bases like triethylamine, morpholine and pyridine were examined in the place of piperidine, morpholine could exhibit a comparable effect with $85 \%$ yield of the product (3a) while the others lagged behind with a great margin (Table 1, entries 12-14). Other catalysts such as $\mathrm{Ce}(\mathrm{OTf})_{3}, \mathrm{Cu}(\mathrm{OTf})_{2}, \mathrm{AlCl}_{3}$, $\mathrm{CuCl}_{2}, \mathrm{CuI}$ and Copper nanopowder were tested in the place of $\mathrm{CuO}$ nanoparticles (Table 1, entries 15-20). To our surprise, only copper nanopowder has exhibited 
Table 1. Optimization for the azide-olefin cycloaddition of $\beta$-bromostyrene and benzyl azide $^{[\mathrm{a}]}$.

\begin{tabular}{|c|c|c|c|c|c|}
\hline Entry & Solvent & Temp $\left({ }^{\circ} \mathrm{C}\right)$ & Catalyst & Yield of $3 \mathrm{a}(\%)^{[\mathrm{b}]}$ & Yield of $4 \mathrm{a}(\%)^{[b]}$ \\
\hline 1 & DMSO & 90 & CNP & 60 & 15 \\
\hline 2 & $n$-Octane & 90 & CNP & 20 & 3 \\
\hline 3 & $\mathrm{CHCl}_{3}$ & 90 & CNP & trace & - \\
\hline 4 & THF & 90 & CNP & trace & - \\
\hline 5 & $\mathrm{CH}_{3} \mathrm{NO}_{2}$ & 90 & CNP & trace & - \\
\hline 6 & Toluene & 90 & CNP & trace & - \\
\hline 7 & DMF & 90 & CNP & trace & - \\
\hline 8 & Water & 90 & CNP & 10 & - \\
\hline 9 & Piperidine & 90 & CNP & 90 & - \\
\hline 10 & Piperidine & 100 & CNP & 95 & - \\
\hline $11^{[\mathrm{c}, \mathrm{d}]}$ & Piperidine & 110 & CNP & 97 & - \\
\hline 12 & $\mathrm{Et}_{3} \mathrm{~N}$ & 110 & CNP & 45 & 7 \\
\hline 13 & Morpholine & 110 & CNP & 85 & - \\
\hline 14 & Pyridine & 110 & CNP & 30 & 10 \\
\hline 15 & Piperidine & 110 & $\mathrm{Ce}(\mathrm{OTf}) 3$ & 50 & 15 \\
\hline 16 & Piperidine & 110 & $\mathrm{Cu}(\mathrm{OTf})_{2}$ & 70 & - \\
\hline 17 & Piperidine & 110 & $\mathrm{AlCl}_{3}$ & 40 & 8 \\
\hline 18 & Piperidine & 110 & $\mathrm{CuCl}_{2}$ & 69 & - \\
\hline 19 & Piperidine & 110 & $\mathrm{CuI}$ & 65 & - \\
\hline 20 & Piperidine & 110 & $\mathrm{Cu}$ nanopowder & 90 & - \\
\hline 21 & Piperidine & 110 & $\mathrm{CuO}$ & 70 & - \\
\hline 22 & - & 110 & CNP & 45 & 12 \\
\hline 23 & Piperidine & 110 & - & 40 & 15 \\
\hline
\end{tabular}

[a] Reaction conditions: $\beta$-Bromostyrene $(0.5 \mathrm{mmol})$, Benzyl azide $(1.0 \mathrm{mmol})$, catalyst $(50 \mathrm{~mol} \%)$ and solvent $(1.0 \mathrm{~mL})$ were heated for $12 \mathrm{~h}$. [b] Isolated yields. [c] Reaction with $0.5 \mathrm{mmol}$ of azide led to $68 \%$ yield of $\mathbf{3 a}$ and $0.75 \mathrm{mmol}$ of azide furnished $84 \%$ yield of 3a after 12h. [d] Upon performing the reaction with 10, 20, 40 and $60 \mathrm{~mol} \%$ of CNP, the yields of 3a were 57, 83, 90 and 97\%, respectively.

comparable efficiency as that of $\mathrm{CuO}$ nanoparticles which is evident from the yield (Table 1, entry 20). However, it is worth mentioning that copper nanopowder is costlier than the $\mathrm{CuO}$ nanoparticles. Most importantly, bulk $\mathrm{CuO}$ also failed to exhibit the efficiency as its nano brother as testified from the poor yield of the product (Table 1, entry 21). The decline of yields of the products observed under solvent-free and catalyst-free conditions, ascertain the crucial role played by the solvent and the catalyst in this protocol (Table 1, entries 22-23).

Having fixed the optimized condition (Table 1, entry 11) for $\mathrm{CuO}$ nanoparticles catalyzed synthesis of 1,4disubstituted 1,2,3-triazoles via azide-olefin cycloaddition of bromoalkenes and organic azides, a variety of olefins and azides were studied and the results were summarized in Table 2. Initially, benzyl azide (2a) was subjected to this reaction condition with various bromoalkenes (Table 2, entries 1-9). As discussed in the optimization part, $\beta$-bromostyrene (1a) furnished $97 \%$ yield of the required 1,2,3-triazole (3a) with benzyl azide (Table 2, entry 1). Methoxy substituent which is a mesomeric electron donor has dramatically boosted up the reaction to an excellent yield (Table 2, entry 2). On the other hand, methyl substituent which is an inductive electron donor has shown a slight lessening in the efficacy of this transformation (Table 2, entry 3 ).

In case of halogen substitutions, chloro substitution has revealed a remarkable improvement of yield than fluoro and bromo substitutions (Table 2, entries 4 6). On the other hand, strongly electron withdrawing nitro group has significantly suppressed the efficiency of this protocol which is evident from the slump of yield to $65 \%$ (Table 2, entry 7 ). When other aromatic substitutions such as naphthyl and thiophenyl were investigated, thiophenyl sored up to a great 
Table 2. $\mathrm{CuO}$ nanoparticles catalyzed synthesis of 1,4disubstituted 1,2,3-triazoles from bromoalkenes and azides ${ }^{[\mathrm{a}]}$.

\begin{tabular}{|c|c|c|c|c|c|}
\hline $\mathrm{R}^{1}$ & $\mathrm{Br}+$ & & $\begin{array}{r}\text { Cu } \\
\text { Nanopa } \\
\text { Piper } \\
110\end{array}$ & $\begin{array}{l}\mathrm{\lrcorner O} \\
\text { articles } \\
\text { ridine } \\
{ }^{\circ} \mathrm{C}\end{array}$ & $\mathrm{R}^{2} \mathrm{~N}^{-}$ \\
\hline Entry & $\mathrm{R}^{1}$ & 1 & $\mathrm{R}^{2}$ & 23 & Yield $(\%)^{[\mathrm{b}]}$ \\
\hline 1 & $\mathrm{Ph}$ & $1 \mathbf{a}$ & $\mathrm{Bn}$ & $2 a 3 a$ & 97 \\
\hline 2 & 4-(MeO)Ph & $1 b$ & $\mathrm{Bn}$ & $2 a 3 b$ & 99 \\
\hline 3 & 4-(Me)Ph & 1c & $\mathrm{Bn}$ & $2 a 3 c$ & 78 \\
\hline 4 & 4-(F)Ph & 1d & $\mathrm{Bn}$ & $2 a 3 d$ & 79 \\
\hline 5 & 4-(Br)Ph & $1 e$ & $\mathrm{Bn}$ & $2 a 3 e$ & 83 \\
\hline 6 & 4-(Cl)Ph & 1f & $\mathrm{Bn}$ & $2 a 3 f$ & 96 \\
\hline 7 & $3-\left(\mathrm{NO}_{2}\right) \mathrm{Ph}$ & $1 \mathrm{~g}$ & $\mathrm{Bn}$ & $2 a 3 g$ & 65 \\
\hline 8 & 2-Napthyl & $1 \mathrm{~h}$ & $\mathrm{Bn}$ & $2 a 3 h$ & 74 \\
\hline 9 & 2-Thiophenyl & $\mathbf{1 i}$ & $\mathrm{Bn}$ & $2 a \quad 3 i$ & 97 \\
\hline 10 & $\mathrm{Ph}$ & $1 \mathbf{a}$ & 4-(Me)Bn & $2 \mathrm{~b} \quad 3 \mathbf{j}$ & 95 \\
\hline 11 & $\mathrm{Ph}$ & $1 \mathbf{a} 4$ & 4-(MeO)Bn & $2 \mathrm{c} 3 \mathrm{k}$ & 99 \\
\hline 12 & $\mathrm{Ph}$ & $\mathbf{1 a}$ & Phenethyl & 2d 31 & 98 \\
\hline 13 & $\mathrm{Ph}$ & $1 \mathbf{a}$ & n-Hexyl & $2 \mathrm{e} 3 \mathrm{~m}$ & 83 \\
\hline 14 & $\mathrm{Ph}$ & $1 \mathbf{a} C$ & $\mathrm{CH}_{2} \mathrm{CO}_{2} \mathrm{Et}$ & $2 \mathbf{f} 3 n^{[c]}$ & 70 \\
\hline 15 & $\mathrm{Ph}$ & $1 \mathbf{a}$ & $\mathrm{Ph}$ & $2 \mathrm{~g} 30$ & 68 \\
\hline 16 & 4-(MeO)Ph & $1 b$ & Phenethyl & $2 d 3 p$ & 76 \\
\hline
\end{tabular}

[a] Reaction conditions: Bromoalkenes $(0.5 \mathrm{mmol})$, organic azide $(1.0 \mathrm{mmol}), \mathrm{CuO}$ Nanoparticles $(50 \mathrm{~mol} \%)$ and piperidine $(1.0 \mathrm{~mL})$ were heated for $12 \mathrm{~h}$. [b] Isolated yields. [c] 2-(4-phenyl-1H-1,2,3-triazol-1-yl)-1-(piperidin-1-yl)ethanone forms as the solvent reacts with the ester group of the triazole.

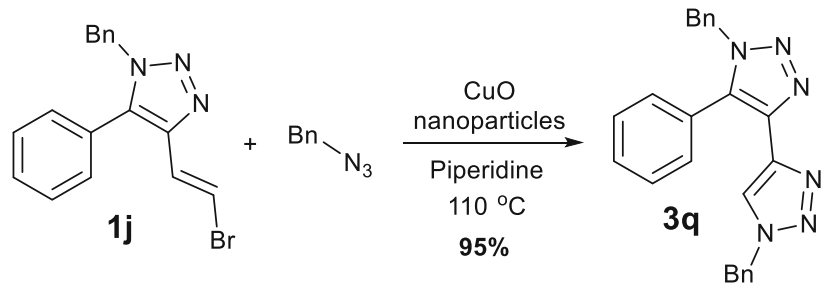

Scheme 2. Synthesis of bis-triazole by azide-olefin cycloaddition of (2-bromovinyl)triazole with benzyl azide.

margin while naphthyl slipped to poor yield (Table 2, entries 8-9). On the other part of this study, fixing the olefin (1a), various azides were subjected to this condition and examined the outcome (Table 2, entries 10-15). Excellent yields of triazoles were registered with methyl and methoxy benzyl azides (Table 2, entries 10-11). In case of aliphatic azides, phenethyl azide (2d) was found to be benign while $n$-hexylazide (2e) was hostile to this reaction condition as reflected in the difference of yields of the products (Table 2, entries 12-13). Being aliphatic and electron deficient, ethyl-2-azidoacetate seemingly suppressed the yield (Table 2, entry 14). Phenyl azide, being aromatic as well as electron deficient, has also markedly retarded
Table 3. Recycling of $\mathrm{CuO}$ nanoparticles.

\begin{tabular}{|c|c|c|c|}
\hline $1 a$ & $\begin{array}{c}+\mathrm{Bn}-\mathrm{N}_{3} \\
2 \mathrm{a}\end{array}$ & $\begin{array}{c}\mathrm{CuO} \\
\text { Nanoparticles } \\
\text { Piperidine } \\
110^{\circ} \mathrm{C}\end{array}$ & $\underbrace{\mathrm{Bn}_{-}-\mathrm{N}}_{3 a}$ \\
\hline Entry & $\begin{array}{l}\text { Catalyst } \\
\text { recovery (\%) }\end{array}$ & $\begin{array}{l}\text { Catalytic } \\
\text { Cycle }\end{array}$ & Yield (\%) \\
\hline $1^{[\mathrm{a}]}$ & 97 & 1 & 97 \\
\hline $2^{[\mathrm{b}]}$ & 92 & 2 & 94 \\
\hline $3^{[\mathrm{b}]}$ & 86 & 3 & 90 \\
\hline $4^{[b]}$ & 82 & 4 & 88 \\
\hline
\end{tabular}

[a] Reaction conditions: Bromoalkenes $(2.5 \mathrm{mmol})$, organic azide $(5.0 \mathrm{mmol}), \mathrm{CuO}$ Nanoparticles $(250 \mathrm{~mol} \%)$ and piperidine $(5.0 \mathrm{~mL})$ were heated for $12 \mathrm{~h}$. [b] The recovered catalyst was under identical reaction conditions to those for the first run.

the efficacy of the protocol since the yield decreased to $68 \%$ (Table 2, entry 15). Unlike its reaction with $\beta$ bromostyrene (1a), phenethyl azide (2d) has furnished a diminished yield of the product when it confronts 4methoxy- $\beta$-bromostyrene (1b) as stated in Table 2 , entry 16. 
Even the (2-bromovinyl)triazole (1j) was submissive to this reaction condition and furnished excellent yield of bis-triazole (3q) by using this protocol (Scheme 2).

Finally, recyclability of the heterogeneous $\mathrm{CuO}$ nanoparticles was also examined. The catalyst was recovered from the reaction mixture after each cycle as follows. The reaction mixture was concentrated in vacuo and diluted with water $(10 \mathrm{~mL})$. The resulting heterogeneous mixture was filtered and the solid residue was washed with ethylacetate and dried in the hot air oven at $110^{\circ} \mathrm{C}$ for $2 \mathrm{~h}$. It was observed that the catalyst remains active even for four cycles (Table 3 ).

\section{Conclusions}

In conclusion, a method commercially available $\mathrm{CuO}$ nanoparticles-catalyzed synthesis of 1,2,3-triazoles via azide-olefin cycloaddition of bromoalkenes and organic azides has been developed and a diverse array of 1,4disubstituted 1,2,3-triazoles is built up. This method is distinct from the existing $\mathrm{Cu}$-catalyzed azide-alkyne cycloaddition due to the accessibility of the starting material and less cytotoxicity of the $\mathrm{CuO}$ nanoparticles than the conventional copper(I) reagents. ${ }^{45}$ This method is different from the existing Pd-catalyzed synthesis of 1,2,3-triazoles from bromoalkenes by the economic viability of the $\mathrm{CuO}$ nanoparticles over the Pd catalysts. This method is also unique from the $t$-BuOK-promoted azide-alkene cycloaddition of bromoalkenes because of its complementary regioselectivity and versatility of azides employed (benzyl, alkyl and aryl). These salient attributes make this method as a highly desirable one among the other existing methods.

\section{Supplementary Information (SI)}

Additional experimental data and spectroscopic characterization data are given. Supplementary Information is available at www.ias.ac.in/chemsci.

\section{Acknowledgements}

We thank the SERB (New Delhi) for financial support (SB/EMEQ-260/2014). D. G. thanks CSIR (New Delhi) for Senior Research Fellowship (09/1166(0001)/2017-EMR-I).

\section{References}

1. Huisgen R 1963 1,3-Dipolar cycloadditions past and future Angew. Chem. Int. Ed. Engl. 2565

2. Huisgen R 1963 Kinetics and mechanism of 1,3-dipolar cycloadditions Angew. Chem. Int. Ed. Engl. 2633

3. Tornøe C W, Christensen C and Meldal M 2002 Peptidotriazoles on solid phase: [1,2,3]-triazoles by regiospecific
copper(I)-catalyzed 1,3-dipolar cycloadditions of terminal alkynes to azides J. Org. Chem. 673057

4. Rostovtsev V V, Green L G, Fokin V V and Sharpless K B 2002 A stepwise Huisgen cycloaddition process: copper(I)-catalyzed regioselective ligation of azides and terminal alkynes Angew. Chem. Int. Edit. 41 2596

5. Agalave S G, Maujan S R and Pore V S 2011 Click chemistry: 1,2,3-triazoles as pharmacophores Chem. Asian J. 62696

6. Kolb H C and Sharpless K B 2003 The growing impact of click chemistry on drug discovery Drug Discov. Today 81128

7. Lutz J-F and Zarafshani Z 2008 Efficient construction of therapeutics, bio conjugates, biomaterials and bioactive surfaces using azide-alkyne "click" chemistry Adv. Drug Deliv. Rev. 60958

8. Kempe K, Krieg A, Becer C R and Schubert U S 2012 Clicking on/with polymers: a rapidly expanding field for the straight forward preparation of novel macromolecular architectures Chem. Soc. Rev. 41176

9. Huo J, Hu H, Zhang M, Hu X, Chen M, Chen D, Liu J, Xiao G, Wang Y and Wen Z 2017 A mini review of the synthesis of poly-1,2,3-triazole-based functional materials $R S C A d v .72281$

10. Beghdadi S, Miladi I A, Addis D, Romdhane H B, Bernardand J and Drockenmuller E 2012 Synthesis and polymerization of C-vinyl- and N-vinyl-1,2,3-triazoles Polym. Chem. 31680

11. Fahrenbach A C and Stoddart J F 2011 Reactions under the click chemistry philosophy employed in supramolecular and mechanostereochemical systems Chem. Asian J. 62660

12. Schulze B and Schubert U S 2014 Beyond click chemistry supramolecular interactions of 1,2,3-triazoles Chem. Soc. Rev. 432522

13. Chattopadhyay B and Gevorgyan V 2012 Transitionmetal-catalyzed denitrogenative transannulation: converting triazoles into other heterocyclic systems Angew. Chem. Int. Edit. 51862

14. Seo B, Jeon W H, Kim J, Kim S and Lee P H 2015 Synthesis of fluorenes via tandem copper-catalyzed $[3+2]$ cycloaddition and rhodium-catalyzed denitrogenative cyclization in a 5-exo mode from 2-ethynylbiaryls and $N$-sulfonyl azides in one pot J. Org. Chem. 80 722

15. Kim C-E, Park Y, Park S and Lee P H 2015 Diastereoselective synthesis of tetrahydrofuranoand tetrahydropyrano-dihydropyrroles containing N,Oacetal moieties via rhodium-catalyzed transannulation of N-sulfonyl-1,2,3-triazoles with oxacycloalkenes $A d v$. Synth. Catal. 357210

16. Fan W-Q and Katritzky A R 1996 In Comprehensive heterocyclic chemistry Vol. II A R Katritzky, C W Rees and E F V Scriven (Ed.) (Oxford: Elsevier) p. 1126

17. Finley K T (Ed.) 1980 In Chemistry of heterocyclic compounds: Triazoles 1,2,3 (New York: Wiley)

18. Zhang L, Chen X, Xue P, Sun H H Y, Williams I D, Sharpless K B, Fokin V V and Jia G 2005 Rutheniumcatalyzed cycloaddition of alkynes and organic azides $J$. Am. Chem. Soc. 12715998 
19. Rasmussen L K, Boren B C and Fokin V V 2007 Ruthenium-catalyzed cycloaddition of aryl azides and alkynes Org. Lett. 95337

20. Boren B C, Narayan S, Rasmussen L K, Zhang L, Zhao H, Lin Z, Jia G and Fokin V V 2008 Ruthenium-catalyzed azide-alkyne cycloaddition: scope and mechanism J. Am. Chem. Soc. 1308923

21. Chen Y, Nie G, Zhang Q, Ma S, Li H and Hu Q 2015 Copper-catalyzed [3+2] cycloaddition/oxidation reactions between nitro-olefins and organic azides: highly regioselective synthesis of $\mathrm{NO}_{2}$-substituted 1,2,3triazoles Org. Lett. 171118

22. Xie Y-Y, Wang Y-C, Qu H-E, Tan X-C, Wang H-S and Pan Y-M 2014 Regioselective synthesis of $\beta$-aryl enaminones and 1,4,5-trisubstituted 1,2,3-triazoles from chalcones and benzyl Azides Adv. Synth. Catal. 3563347

23. Rohilla S, Patel S S and Jain N 2016 Copper acetate catalyzed regioselective synthesis of substituted 1,2,3-triazoles: A versatile azide-alkene cycloaddition/oxidation approach Eur. J. Org. Chem. 2016847

24. Janreddy D, Kavala V, Kuo C-W, Chen W-C, Ramesh C, Kotipalli T, Kuo T-S, Chen M-L, He C-H and Yao C-F 2013 Copper(I)-catalyzed aerobic oxidative azidealkene cycloaddition: an efficient synthesis of substituted 1,2,3-triazoles Adv. Synth. Catal. 3552918

25. Zhang Y, Li X, Li J, Chen J, Meng X, Zhao M and Chen B $2012 \mathrm{CuO}$-promoted construction of $\mathrm{N}$-2-arylsubstituted-1,2,3-triazoles via azide-chalcone oxidative cycloaddition and post-triazole arylation Org. Lett. 1426

26. Kamal A and Swapna P 2013 An improved iron-mediated synthesis of $N$-2-arylsubstituted 1,2,3triazoles $R S C A d v .37419$

27. Peng $W$ and Zhu S 2003 Efficient synthesis of 5fluoroalkylated $1 H-1,2,3$-triazoles and application of the bromo difluoromethylated triazole to the synthesis of novel bicyclic gem-difluorinated $1 H$-pyrano[3,4d][1,2,3]-triazol-4-one compounds Tetrahedron $\mathbf{5 9} 4395$

28. Roque D R, Neill J L, Antoon J W and Stevens E P 2005 Synthesis of 1,2,3-triazoles by cycloadditions of azides with enol ethers Synthesis 2497

29. Hansen S G and Jensen H H 2009 Microwave irradiation as an effective means of synthesizing unsubstituted $N$-linked 1,2,3-triazoles from vinyl acetate and azides Synlett. 3275

30. Amantini D, Fringuelli F, Piermatti O, Pizzo F, Zunino E and Vaccaro L 2005 Synthesis of 4-aryl-1 $H-1,2,3-$ triazoles through TBAF-catalyzed [3+2] cycloaddition of 2-aryl-1-nitroethenes with $\mathrm{TMSN}_{3}$ under solvent-free conditions J. Org. Chem. 706526

31. Sengupta S, Duan H, Lu W, Petersen J L and Shi X 2008 One step cascade synthesis of 4,5-disubstituted-1,2,3(NH)-triazoles Org. Lett. 101493

32. Wang Y-C, Xie Y-Y, Qu H-E, Wang H-S, Pan Y-M and Huang F-P 2014 Ce(OTf) 3 -catalyzed [3+2] cycloaddition of azides with nitroolefins: Regioselective synthesis of 1,5-disubstituted 1,2,3-triazoles J. Org. Chem. 79 4463
33. Hu Q, Liu Y, Deng X, Li Y and Chen Y 2016 Aluminium(III) chloride-catalyzed three-component condensation of aromatic aldehydes, nitroalkanes and sodium azide for the synthesis of 4-aryl- $\mathrm{NH}-1,2,3$ triazoles Adv. Synth. Catal. 3581689

34. Zhang H, Dong D-Z and Wang Z-L 2016 Direct synthesis of $N$-unsubstituted 4-aryl-1,2,3-triazoles mediated by Amberlyst-15 Synthesis $\mathbf{4 8} 131$

35. Kayet A and Pathak T 2013 1,5-Disubstituted 1,2,3triazolylation at $\mathrm{C}_{1}, \mathrm{C}_{2}, \mathrm{C}_{3}, \mathrm{C}_{4}$, and $\mathrm{C}_{6}$ of pyranosides: a metal-free route to triazolylated monosaccharides and Triazole-linked disaccharides J. Org. Chem. 78 9865

36. Sahu D, Dey S, Pathak T and Ganguly B 2014 Regioselectivity of vinyl sulfone based 1,3-dipolar cycloaddition reactions with sugar azides by computational and experimental studies Org. Lett. 162100

37. John J, Thomas J and Dehaen W 2015 Organo catalytic routes toward substituted 1,2,3-triazoles Chem. Commun. 5110797

38. Gangaprasad D, Paul Raj J, Kiranmye T, Sagubar Sadik S and Elangovan J 2015 A new paradigm of copper oxide nanoparticles catalyzed reactions: synthesis of 1,2,3triazoles through oxidative azide-olefin cycloaddition RSC Adv. 563473.

39. Gangaprasad D, Paul Raj J, Kiranmye T, Sasikala R, Karthikeyan K, Kutti Rani S and Elangovan J 2016 A tunable route to oxidative and eliminative [3+2] cycloadditions of organic azides with nitroolefins: $\mathrm{CuO}$ nanoparticles catalyzed synthesis of 1,2,3-triazoles under solventfree condition Tetrahedron. Lett 573105

40. Rout L, Sen T. K and Punniyamurthy T 2007 Efficient $\mathrm{CuO}$-nanoparticle-catalyzed C-S cross-coupling of thiols with iodobenzene Angew. Chem. Int. Edit. 46 5583

41. Jammi S, Sakthivel S, Rout L, Mukherjee T, Mandal S, Mitra R, Saha P and Punniyamurthy T 2009 $\mathrm{CuO}$ nanoparticles catalyzed C-N, C-O, and C-S crosscoupling reactions: scope and mechanism J. Org. Chem. 741971

42. Barluenga J, Valdés C, Beltran G, Escribano M and Aznar F 2006 Developments in Pd catalysis: synthesis of $1 \mathrm{H}$-1,2,3-triazoles from sodium azide and alkenyl bromides Angew. Chem. Int. Edit. 456893

43. Wu L, Chen Y, Luo J, Sun Q and Peng Mand Lin Q 2014 Base-mediated reaction of vinyl bromides with aryl azides: one-pot synthesis of 1,5-disubstituted 1,2,3triazoles Tetrahedron. Lett. 553847

44. Wang X, Kuang C and Yang Q 2012 Coppercatalyzed synthesis of 4-aryl-1H-1,2,3-triazoles from 1,1-dibromoalkenes and sodium azide Eur. J. Org. Chem. 2012424

45. Zhang Z, Dong C, Yang C, Hu D, Long J, Wang L, Li H, Chen Y and Kong D 2010 Stabilized copper(I) oxide nanoparticles catalyze azide-alkyne click reactions in water Adv. Synth. Catal. 352 1600 